\title{
Early histologic findings of pulmonary SARS-CoV-2 infection detected in a surgical specimen
}

\author{
Angelina Pernazza ${ }^{1}$. Massimiliano Mancini ${ }^{2} \cdot$ Emma Rullo $^{3} \cdot$ Massimiliano Bassi $^{4} \cdot$ Tiziano De Giacomo $^{4}$. \\ Carlo Della Rocca ${ }^{1} \cdot$ Giulia d'Amati $^{3} \mathbb{B}$
}

Received: 2 April 2020 /Revised: 11 April 2020 / Accepted: 26 April 2020/Published online: 30 April 2020

(C) Springer-Verlag GmbH Germany, part of Springer Nature 2020

\begin{abstract}
Despite the current pandemic season, reports on pathologic features of coronavirus disease 19 (Covid-19) are exceedingly rare at the present time. Here we describe the pathologic features of early lung involvement by Covid-19 in a surgical sample resected for carcinoma from a patient who developed SARS-CoV-2 infection soon after surgery. The main histologic findings observed were pneumocyte damage, alveolar hemorrhages with clustering of macrophages, prominent and diffuse neutrophilic margination within septal vessels, and interstitial inflammatory infiltrates, mainly represented by CD8+ T lymphocytes. These features are similar to those previously described in SARS-CoV-1 infection. Subtle histologic changes suggestive pulmonary involvement by Covid-19 may be accidentally encountered in routine pathology practice, especially when extensive sampling is performed for histology. These findings should be carefully interpreted in light of the clinical context of the patient and could prompt a pharyngeal swab PCR test to rule out the possibility of SARS-CoV-2 infection in asymptomatic patients.
\end{abstract}

Keywords SARS-CoV-2 $\cdot$ Covid-19 $\cdot$ Pathology $\cdot$ Lung histology

\section{Introduction}

Coronavirus disease 19 (Covid-19) is a global pandemic caused by the severe acute respiratory syndrome coronavirus-2 (SARS-CoV-2). According to the WHO Covid-19 situation report of March 29, Italy is the most affected European country, with 92.472 total cases and 10.023 deaths. The virus is transmitted mainly by inhalation of respiratory droplets from both symptomatic and asymptomatic patients. Fever, fatigue, and dry cough are the most common symptoms at clinical presentation.

Giulia d'Amati

giulia.damati@uniroma1.it

1 Department of Medico-Surgical Sciences and Biotechnologies, Polo Pontino-Sapienza University, 04100 Latina, Italy

2 Division of Morphologic and Molecular S. Andrea Hospital, Sapienza, University of Rome, 00189 Rome, Italy

3 Department of Radiological, Oncological and Pathological Sciences, Sapienza, University of Rome, Policlinico Umberto I, Viale Regina Elena 324, 00161 Rome, Italy

4 Department of General and Specialistic Surgery "P. Stefanini”, Sapienza, University of Rome, 00161 Rome, Italy
Approximately $13-20 \%$ of infected individuals develop severe respiratory symptoms with radiological findings of interstitial involvement, requiring assisted oxygenation [1-3]. A low number of routine autopsies is performed due to the high infectivity of the disease; accordingly, there are only a few reports in medical literature describing the histopathologic findings of SARSCoV-2 infection $[4,5]$. More in-depth investigations only come from SARS-Coronavirus outbreaks in the past [6].

Here we describe the histologic features of early lung involvement by Covid-19 in a surgical sample resected for carcinoma from a patient who later developed SARS-CoV-2 infection.

\section{Case report}

A 61-year-old male smoker was admitted to our hospital for surgical treatment of a lung adenocarcinoma, diagnosed on biopsy. His clinical history was positive for a MALT lymphoma diagnosed 6 months before, with complete remission after therapy. According to preoperatory imaging, obtained 3 weeks before surgery, 
the lesion was localized in the right inferior lobe, measured $2 \mathrm{~cm}$ and showed a solid appearance. There were no ground glass opacities. At admission, the patient was in good general condition, afebrile. A thoracoscopic lobectomy with lymph node dissection (stations $2,4,7,8$, 9 , and 10) was performed, without intraoperative complications. After surgery, the patient developed progressive lymphopenia (with values ranging between 920 and 340 lymphocytes $/ \mu \mathrm{L}$ from the first to the fifth postoperative day) and, on the scheduled date for discharge, had an episode of fever $\left(38{ }^{\circ} \mathrm{C}\right)$ in the absence of respiratory symptoms. Thus, his antibiotic therapy was changed, with no improvement. A pharyngeal swab PCR test was performed, which confirmed the suspicion of SARS-CoV-2 infection. The patient was immediately transferred to the isolation ward where he developed cough, dyspnea, fatigue, and high fever $\left(38-39{ }^{\circ} \mathrm{C}\right)$. $\mathrm{SpO} 2$ was stable between 96 and 98\%. Both white blood cells $(2570 / \mu \mathrm{L})$ and lymphocytes counts were low $(280 / \mu \mathrm{L})$. A chest CT scan showed post-resection changes and bilateral, peripheral, and ill-defined groundglass opacities, mainly involving the lower lobe, consistent with Covid-19 pneumonia (Fig. 1a).

Since oxygen saturation had dropped to $35 \%$, he received supplemental oxygen through a CPAP mask. On a second CT scan, performed 1 week later, the groundglass opacities were enlarged, with areas of consolidation (Fig. 1b). He received a therapy based on antibiotics (meropenem and bactrim), antiviral drugs (acyclovir and darunavir), and on two recently approved experimental drugs for SARS-CoV-2 infection: tocilizumab (commonly used for the therapy of rheumatoid arthritis) and chloroquine hydrate (a common antimalarial drug), with an improvement of his conditions and clinical remission in the following weeks.

Histologic examination of the formalin-fixed specimen confirmed the diagnosis of lung adenocarcinoma, with a predominant acinar pattern. The lung parenchyma surrounding the neoplasia showed diffuse hemorrhages and clusters of alveolar macrophages, with occasional multinucleated cells (Fig. 2a). At higher magnification, there was evidence of both diffuse pneumocyte loss and reactive hyperplasia, with focal pneumocytes showing nuclear inclusions (Fig. 3a, b). There were scanty fibrin depositions on the alveolar surfaces, in the absence of hyaline membranes (Fig. 2c). The interstitium showed edema and a mild inflammatory infiltrate, mainly composed of cytotoxic (CD8+) T lymphocytes (Fig. 3c-f). Interestingly, there were diffuse aspects of neutrophil margination within small arterioles (Fig. 3d). Occasional fibrous plugs were also observed (Fig. 3c). Interstitial changes were more marked in the subpleural area, where mild fibrous thickening of alveolar septa was also observed (Fig. 2b).

Finally, areas of smoking-related interstitial fibrosis, consistent with the patient's habits, were also present.

\section{Discussion}

In this report, we provide a detailed analysis of the early histologic changes of pulmonary SARS-CoV-2 infection.

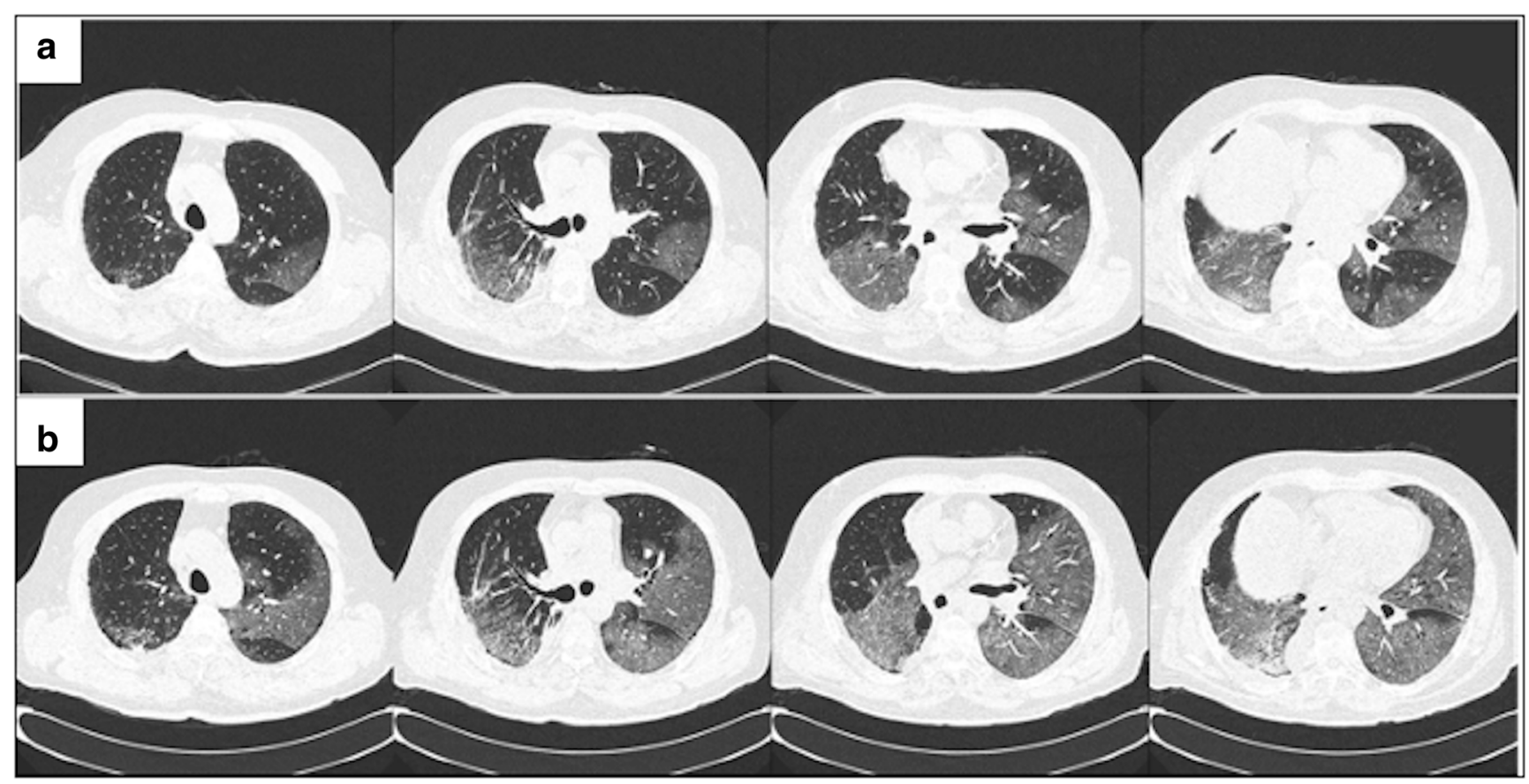

Fig. 1 High-resolution CT scans performed one (a) and two (b) weeks after surgery, respectively show ground glass bilateral opacities, enlarging with time, with the additional finding of areas of consolidation 


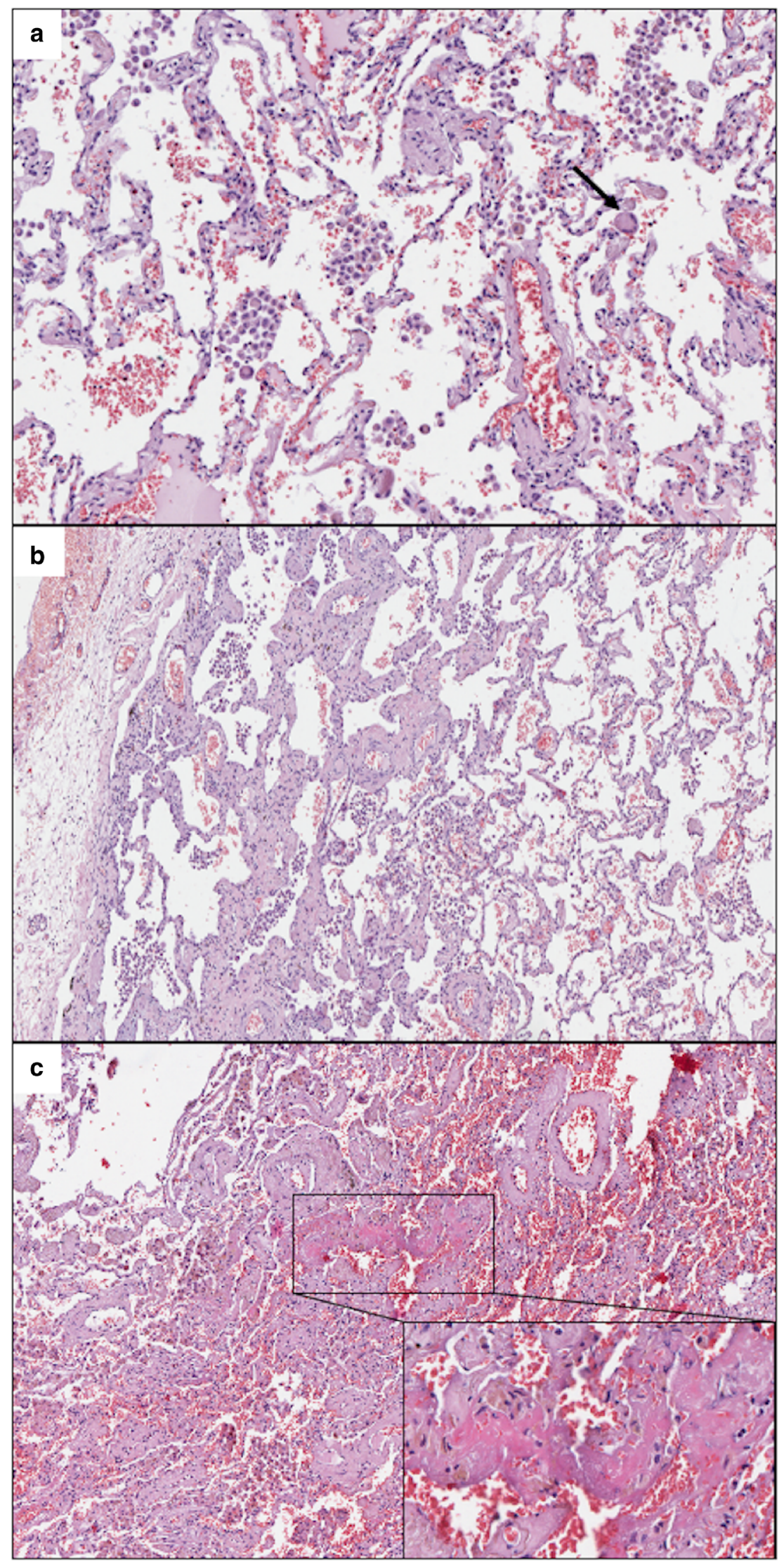

Fig. 2 a $(\times 20)$ Alveolar hemorrhages and clusters of macrophages with occasional giant cells (arrow). b $(\times 10)$ The alveolar septa show mild fibrous thickening limited to the subpleural area. $\mathbf{c}(\times 10)$ Fibrin deposits admixed with red blood cells and inflammatory infiltrates $(H \& E)$ 


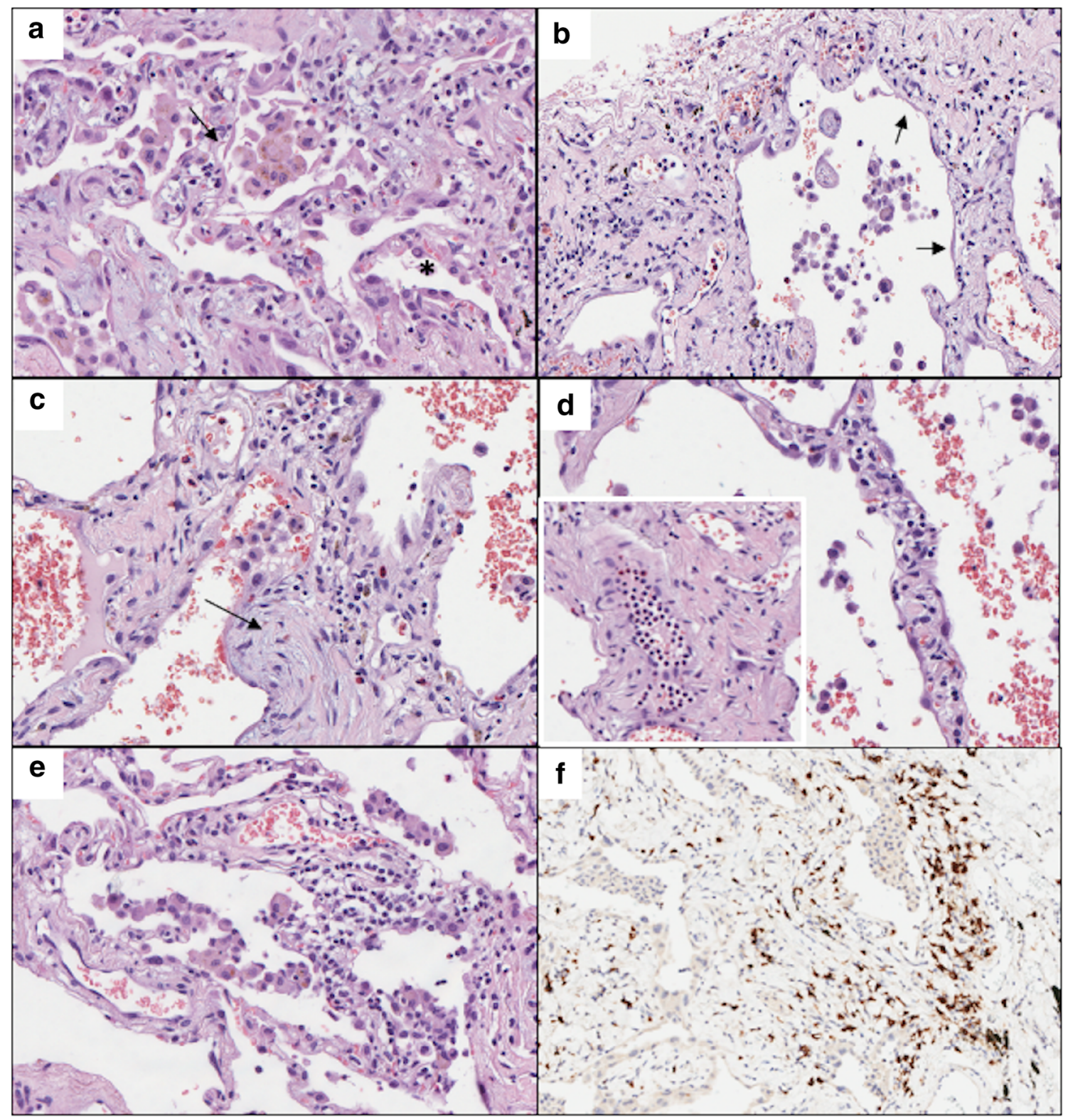

Fig. 3 a $(\times 40)$ Pneumocyte desquamation (arrow) and reactive hyperplasia with focal nuclear inclusion (asterisk). Abundant hemosiderin pigment is present within alveolar macrophages. b $(\times 40)$ Diffuse pneumocyte loss (arrows) and alveolar septal thickening. c $(\times 40)$ Inflammatory infiltrates and fibrous plugs as those observed in organizing pneumonia (arrow). d $(\times 40)$ Neutrophilic vascular margination and edema of the alveolar wall. e Diffuse interstitial lymphocyte infiltrate and intra-alveolar macrophages $(\mathrm{H} \& \mathrm{E}) . \mathbf{f}(\times 20) \mathrm{CD} 8$ immunostaining shows a prevalence of cytotoxic $\mathrm{T}$ lymphocytes (immunoperoxidase stain)
Similar to the two previously published cases from China [5], the virus-related alterations were an incidental finding in a surgical sample sent to the Pathology Department for routine diagnostic work-up of lung cancer, before the onset of clear clinical signs and symptoms of Covid-19. As early radiological changes have been demonstrated in the asymptomatic phase of infection [7], we emphasize the importance of recognizing early subtle histological changes in lung surgical specimens.
The main histologic findings herein described are pneumocyte damage, alveolar hemorrhage and clustering of macrophages, and interstitial inflammatory infiltrates, with prominent and diffuse neutrophilic margination within septal vessels. These features are similar to those described in SARS-CoV-2 infection and are consistent with the previously postulated mechanisms underlying pulmonary damage in SARS $[8,9]$ : the interaction between the virus and both pneumocytes and alveolar macrophages triggers a cascade of immunological events, with the production of cytokines and 
chemokines and expression of adhesion molecules by pneumocytes. This in turn drives an inflammatory response with prominent macrophages, neutrophils, and T CD8+ lymphocytes, which is responsible for the diffuse alveolar damage observed in the more severe and advanced stage of the disease. Indeed, diffuse alveolar damage (DAD) has been reported as a common autopsy finding in SARS-CoV [6, 10-13]. A recent autopsy report highlights the finding of diffuse alveolar damage as the major lung feature also in severe SARS-CoV-2 infection [4]. However, the absence of DAD does not rule out the possibility of Covid-19 pneumonia, in the early stage of disease [12].

Interestingly, in our case, histologic findings were more marked and diffused in the subpleural region. This is consistent with the higher frequency of peripheral and subpleural involvement on high-resolution CT scan recently reported in a cohort of 81 patients with Covid-19 pneumonia [3].

Covid-19 has been shown to strike elderly patients with higher frequency and worse clinical outcome especially in the presence of comorbidities (e.g., chronic obstructive pulmonary disease and malignancy) [14, 15]. A male predilection has also been recognized [14]. We speculate that the rapid disease evolution observed in our patient could be due to pre-existing lung alterations induced by smoking, although there are no evidences supporting a correlation between smoking and severity of the disease [16].

In conclusion, during the current pandemic season, subtle pulmonary histologic changes suggestive of SARS-CoV-2 infection may be accidentally encountered in routine pathology practice, especially if extensive sampling is performed for histology.

These findings should be carefully interpreted in light of the clinical context of the patient and could prompt a pharyngeal swab PCR test to rule out the possibility of SARS-CoV-2 infection in asymptomatic patients.

Authors' contributions Pernazza Angelina contributed to the analysis of the pathologic findings and to manuscript writing; Mancini Massimiliano contributed to the pathologic analysis and to manuscript writing; Rullo Emma contributed to the analysis of the pathologic findings and to manuscript writing; Bassi Massimiliano collected and critically analyzed clinical data; De Giacomo Tiziano collected and critically analyzed clinical data; Della Rocca Carlo revised the work critically for important intellectual content; and d'Amati Giulia contributed to the analysis of the pathologic findings and to manuscript writing.

\section{Compliance with ethical standards}

The study complies with ethical standards with both Institutions. The patient gave his informed consent.

Conflict of interest The authors declare that they have no conflict of interest.

\section{References}

1. Huang C, Wang Y, Li X, Ren L, Zhao J, Hu Y, Zhang L, Fan G, Xu J, Gu X, Cheng Z, Yu T, Xia J, Wei Y, Wu W, Xie X, Yin W, Li H, Liu M, Xiao Y, Gao H, Guo L, Xie J, Wang G, Jiang R, Gao Z, Jin Q, Wang J, Cao B (2020) Clinical features of patients infected with 2019 novel coronavirus in Wuhan, China. Lancet 395(10223):497506. https://doi.org/10.1016/S0140-6736(20)30183-5

2. Wang D, Hu B, Hu C, Zhu F, Liu X, Zhang J, Wang B, Xiang H, Cheng Z, Xiong Y, Zhao Y, Li Y, Wang X, Peng Z (2020) Clinical characteristics of 138 hospitalized patients with 2019 novel coronavirus-infected pneumonia in Wuhan, China. JAMA. https:// doi.org/10.1001/jama.2020.1585

3. Shi H, Han X, Jiang N, Cao Y, Alwalid O, Gu J, Fan Y, Zheng C (2020) Radiological findings from 81 patients with COVID-19 pneumonia in Wuhan, China: a descriptive study. Lancet Infect Dis 20(4):425-434. https://doi.org/10.1016/S1473-3099(20) 30086-4

4. Xu Z, Shi L, Wang Y, Zhang J, Huang L, Zhang C, Liu S, Zhao P, Liu H, Zhu L, Tai Y, Bai C, Gao T, Song J, Xia P, Dong J, Zhao J, Wang FS (2020) Pathological findings of COVID-19 associated with acute respiratory distress syndrome. Lancet Respir Med. https://doi.org/10.1016/S2213-2600(20)30076-X

5. Tian S, Hu W, Niu L, Liu H, Xu H, Xiao SY (2020) Pulmonary pathology of early-phase 2019 novel coronavirus (COVID-19) pneumonia in two patients with lung cancer. J Thorac Oncol 15: 700-704. https://doi.org/10.1016/j.jtho.2020.02.010

6. Lang ZW, Zhang LJ, Zhang SJ, Meng X, Li JQ, Song CZ, Sun L, Zhou YS, Dwyer DE (2003) A clinicopathological study of three cases of severe acute respiratory syndrome (SARS). Pathology 35(6):526-531. https://doi.org/10.1080/00313020310001619118

7. Inui S, Fujikawa A, Jitsu M, Kunishima N, Watanabe S, Suzuki Y, Umeda S, Uwabe Y (2020) Chest CT findings in cases from the cruise ship "diamond princess" with coronavirus disease 2019 (COVID-19), Mar 17. https://doi.org/10.1148/ryct.2020200110

8. Yen YT, Liao F, Hsiao CH, Kao CL, Chen YC, Wu-Hsieh BA (2006) Modeling the early events of severe acute respiratory syndrome coronavirus infection in vitro. J Virol Mar 80(6):2684-2693. https://doi.org/10.1128/JVI.80.6.2684-2693.2006

9. Zhao JM, Zhou GD, Sun YL, Wang SS, Yang JF, Meng EH, Pan D, Li WS, Zhou XS, Wang YD, Lu JY, Li N, Wang DW, Zhou BC, Zhang TH (2003) Clinical pathology and pathogenesis of severe acute respiratory syndrome. Zhonghua Shi Yan He Lin Chuang Bing Du Xue Za Zhi 17(3):217-221

10. Pei F, Zheng J, Gao ZF, Zhong YF, Fang WG, Gong EC, Zou WZ, Wang SL, Gao DX, Xie ZG, Lu M, Shi XY, Liu CR, Yang JP, Wang YP, Han ZH, Shi XH, Dao WB, Gu J (2005) Lung pathology and pathogenesis of severe acute respiratory syndrome: a report of six full autopsies. Zhonghua Bing Li Xue Za Zhi 34(10):656-660

11. Hsiao CH, Chang MF, Hsueh PR, Su IJ (2005) Immunohistochemical study of severe acute respiratory syndrome-associated coronavirus in tissue sections of patients. $\mathrm{J}$ Formos Med Assoc 104(3):150-156

12. Hsiao CH, Wu MZ, Chen CL, Hsueh PR, Hsieh SW, Yang PC, Su IJ (2005) Evolution of pulmonary pathology in severe acute respiratory syndrome. J Formos Med Assoc 104(2):75-81

13. Franks TJ, Chong PY, Chui P, Galvin JR, Lourens RM, Reid AH, Selbs E, McEvoy CP, Hayden CD, Fukuoka J, Taubenberger JK, Travis WD (2004) Lung pathology of severe acute respiratory syndrome (SARS): a study of 8 autopsy cases from Singapore. Hum Pathol 34(8):743-748. Erratum in: Hum Pathol Jan;35(1):138. https://doi.org/10.1016/s0046-8177(03)00367-8

14. Cai $\mathrm{H}$ (2020) Sex difference and smoking predisposition in patients with COVID-19. Lancet Respir Med 8:e20. https://doi.org/10. 1016/S2213-2600(20)30117-X 
15. Guan WJ, Liang WH, Zhao Y, Liang HR, Chen ZS, Li YM, Liu XQ, Chen RC, Tang CL, Wang T, Ou CQ, Li L, Chen PY, Sang L, Wang W, Li JF, Li CC, Ou LM, Cheng B, Xiong S, Ni ZY, Xiang J, Hu Y, Liu L, Shan H, Lei CL, Peng YX, Wei L, Liu Y, Hu YH, Peng P, Wang JM, Liu JY, Chen Z, Li G, Zheng ZJ, Qiu SQ, Luo J, Ye CJ, Zhu SY, Cheng LL, Ye F, Li SY, Zheng JP, Zhang NF, Zhong NS, He JX (2020) Comorbidity and its impact on 1590 patients with Covid-19 in China: a nationwide analysis. Eur Respir J. https://doi.org/10.1183/13993003.00547-2020
16. Lippi G, Henry BM (2020) Active smoking is not associated with severity of coronavirus disease 2019 (COVID-19). Eur J Intern Med. https://doi.org/10.1016/j.ejim.2020.03.014

Publisher's note Springer Nature remains neutral with regard to jurisdictional claims in published maps and institutional affiliations. 